\title{
Long-Term Evaluation of the Ventricular Defibrillation Energy Requirement
}

\author{
TAKASHI TOKANO, M.D., FRANK PELOSI, M.D., MATTHEW FLEMMING, M.D., \\ LAURA HORWOOD, R.N., JOSEPH J. SOUZA, M.D., ADAM ZIVIN, M.D., \\ BRADLEY P. KNIGHT, M.D., RAJIVA GOYAL, M.D., K. CHING MAN, D.O., \\ FRED MORADY, M.D., and S. ADAM STRICKBERGER, M.D. \\ From the Division of Cardiology, Department of Internal Medicine, \\ University of Michigan Medical Center, Ann Arbor, Michigan
}

\begin{abstract}
Defibrillation Energy Requirements. Introduction: Defibrillation energy requirements in patients with nonthoracotomy defibrillators may increase within several months after implantation. However, the stability of the defibrillation energy requirement beyond 1 year has not been reported. The purpose of this study was to characterize the defibrillation energy requirement during 2 years of clinical follow-up.

Methods and Results: Thirty-one consecutive patients with a biphasic nonthoracotomy defibrillation system underwent defibrillation energy requirement testing using a step-down technique $(20,15,12,10,8,6,5,4,3,2$, and $1 \mathrm{~J})$ during defibrillator implantation, and then 24 hours, 2 months, 1 year, and 2 years after implantation. The mean defibrillation energy requirement during these evaluations was $10.9 \pm 5.5 \mathrm{~J}, 12.3 \pm 7.3 \mathrm{~J}, 11.7 \pm 5.6 \mathrm{~J}, 10.2 \pm 4.0 \mathrm{~J}$, and $11.7 \pm 7.4 \mathrm{~J}$, respectively $(P=0.4)$. The defibrillation energy requirement was noted to have increased by $10 \mathrm{~J}$ or more after 2 years of follow-up in five patients. In one of these patients, the defibrillation energy requirement was no longer associated with an adequate safety margin, necessitating revision of the defibrillation system. There were no identifiable clinical characteristics that distinguished patients who did and did not develop a 10-J or more increase in the defibrillation energy requirement.

Conclusion: The mean defibrillation energy requirement does not change significantly after 2 years of biphasic nonthoracotomy defibrillator system implantation. However, approximately $15 \%$ of patients develop a $10-\mathrm{J}$ or greater elevation in the defibrillation energy requirement, and 3\% may require a defibrillation system revision. Therefore, a yearly evaluation of the defibrillation energy requirement may be appropriate. (J Cardiovasc Electrophysiol, Vol. 9, pp. 916-920, September 1998)
\end{abstract}

defibrillation threshold, implantable cardioverter defibrillator, defibrillation safety margin

\section{Introduction}

Defibrillation energy requirements in patients with nonthoracotomy defibrillators may increase within several months of device implantation..$^{1-7}$ An acute elevation in the defibrillation energy requirement may occur with monophasic defibrillation ${ }^{1-4,67}$ and, to a lesser extent, with biphasic de-

Address for correspondence: S. Adam Strickberger, M.D., University of Michigan Medical Center, 1500 East Medical Center Dr., Ann Arbor, MI 48109-0022. Fax: 734-936-7026.

Manuscript received 30 April 1998; Accepted for publication 29 June 1998. fibrillation..$^{5,6,8}$ However, the long-term stability of the defibrillation energy requirement has not been studied. The purpose of this study was to characterize the defibrillation energy requirement during the 2 years after defibrillator implantation.

\section{Methods}

\section{Patient Population}

The study population consisted of 31 consecutive patients who underwent implantation of a biphasic defibrillator and a nonthoracotomy lead 
system. Consecutive patients (mean age $64 \pm 9$ years; 28 men) who underwent device implantation and were followed for 2 years at this institution were included. Twenty-eight patients had coronary artery disease, and three had a nonischemic cardiomyopathy. The mean left ventricular ejection fraction was $0.28 \pm 0.10$. Seven patients were treated with amiodarone throughout the follow-up period. Amiodarone therapy was discontinued after defibrillator implantation in one patient. During the follow-up period, amiodarone therapy was initiated in three patients, and sotalol therapy was initiated in one patient.

\section{Defibrillation System}

A defibrillator with a truncated, fixed-tilt biphasic waveform with a first phase tilt of $60 \%$ and a second phase tilt of 50\% (models 1625, 1715, 1720, and 1740; Cardiac Pacemakers, Inc. [CPI], St. Paul, MN, USA) was implanted in all patients. The transvenous defibrillation lead was equipped with a 617$\mathrm{mm}^{2}$ proximal electrode and a $316-\mathrm{mm}^{2}$ distal electrode (CPI models 74, 75, and 115). A dual-coil transvenous defibrillation lead with a distal electrode of $295 \mathrm{~mm}^{2}$ was implanted in one patient (CPI model 64). A subcutaneous array (CPI model 49) was used in two patients.

\section{Defibrillation Energy Requirement Testing}

All shocks were delivered directly from the implantable defibrillator. A step-down protocol was utilized to determine the defibrillation energy requirement. The defibrillation energy requirement was defined as the lowest energy successful at terminating ventricular fibrillation. Shock energies of $20,15,12,10,8,6,5,4,3,2$, and $1 \mathrm{~J}$ were delivered until ventricular fibrillation failed to convert. Ventricular fibrillation was induced with a 15$\mathrm{V}$ pulse delivered every $30 \mathrm{msec}$, with a duration of $1.1 \mathrm{msec}$ for 1 to 3 seconds. Shocks were delivered after ventricular fibrillation was sensed and the defibrillator charged. The defibrillation energy requirement was determined during implantation, and then 24 hours, 2 months, 1 year, and 2 years later. The first shock energy during each defibrillation energy requirement evaluation was equal to the previously determined defibrillation energy requirement. The shock impedance, pacing threshold, and pacing impedance also were noted at each evaluation. An adequate defibrillation safety margin was defined as a defibrillation energy requirement at least $10 \mathrm{~J}$ less than the maximum out- put of the defibrillator. During follow-up, the first shock energy for the treatment of ventricular fibrillation was programmed at twice the defibrillation energy requirement or at the defibrillation energy requirement plus $10 \mathrm{~J}$, whichever was less.

\section{Statistical Analysis}

Continuous variables are expressed as mean \pm $1 \mathrm{SD}$ and were compared using a paired or unpaired $t$-test, as appropriate. Multiple continuous variables were compared by ANOVA, and then by individual paired $t$-tests when the ANOVA result was statistically significant. Nominal values were compared with contingency table analysis. The relationship between two continuous variables was assessed with a linear regression analysis. $\mathrm{P}<0.05$ was considered statistically significant.

\section{Results}

\section{Mean Defibrillation Energy Requirement During Follow-Up}

The mean defibrillation energy requirement at the time of implantation was $10.9 \pm 5.5 \mathrm{~J}$. The mean defibrillation energy requirements at 24 hours, 2 months ( $67 \pm 12$ days), 1 year ( $383 \pm 82$ days), and 2 years ( $748 \pm 60$ days) after implantation were $12.3 \pm 7.3 \mathrm{~J}, 11.7 \pm 5.6 \mathrm{~J}, 10.2 \pm 4.0 \mathrm{~J}$, and 11.7 $\pm 7.4 \mathrm{~J}$, respectively $(\mathrm{P}=0.4$; Fig. 1$)$. The shock impedance was $43.6 \pm 5.5 \Omega$ during defibrillator implantation, $43.0 \pm 6.6 \Omega$ at 24 hours, $46.9 \pm 7.5$ $\Omega$ at 2 months, $47.0 \pm 7.6 \Omega$ at 1 year, and $47.8 \pm$

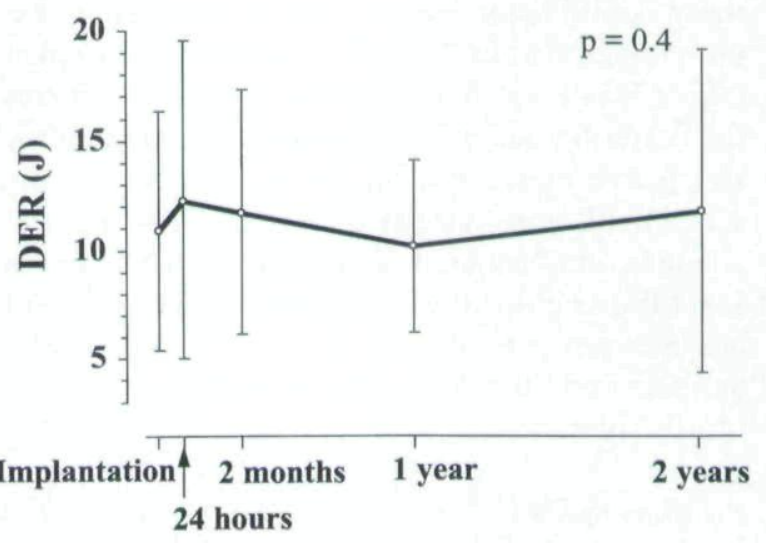

Figure 1. The mean defibrillation energy requirement $(D E R)$ in 31 patients during defibrillator implantation, and 24 hours, 2 months, 1 year, and 2 years later. The mean defibrillation energy requirement did not change during this time $(P=0.4)$. 
$7.0 \Omega$ at 2 years after defibrillator implantation $(\mathrm{P}$ $<0.01)$. The increase in shocking impedance occurred 2 months after defibrillator implantation (P $<0.01)$. The pacing threshold $(\mathrm{P}<0.01)$ and pacing impedance $(\mathrm{P}<0.01)$ increased within 2 months of defibrillator implantation.

A 10-J or greater increase in the defibrillation energy requirement occurred in five patients at the 2-year evaluation (Fig. 2). The mean defibrillation energy requirement at the time of implantation was $11.0 \pm 5.5 \mathrm{~J}$ among these patients as compared with $10.8 \pm 5.6 \mathrm{~J}$ among the remaining 26 patients $(\mathrm{P}=1.0)$. One of the five patients in whom the defibrillation energy requirement increased by 10 $\mathrm{J}$ or more required a defibrillation system revision to achieve a defibrillation energy requirement that was at least $10 \mathrm{~J}$ less than the defibrillator's maximum available energy. To maintain an adequate defibrillation energy requirement in the other four patients, the first shock energy was reprogrammed from $25.0 \pm 4.1 \mathrm{~J}$ to $31.8 \pm 4.5 \mathrm{~J}$. There was no difference in the pacing threshold or pacing impedance at implant or during follow-up in the patients who developed an elevated defibrillation energy requirement. There were no significant differences in the clinical characteristics between patients who did and did not develop a 10-J or greater increase in the defibrillation energy requirement (Table 1).

\section{Discussion}

\section{Major Findings}

The results of this study demonstrate that the mean defibrillation energy requirement usually does not change within 2 years of defibrillator implantation. However, in approximately $15 \%$ of patients, the defibrillation energy requirement may increase by $10 \mathrm{~J}$ or more, and $3 \%$ of patients may require a defibrillation system revision to maintain an adequate defibrillation safety margin. There are no identifiable clinical characteristics that differentiate between patients who do and do not develop an increase in the defibrillation energy requirement of $10 \mathrm{~J}$ or more.

\section{Previous Studies}

The defibrillation energy requirement associated with epicardial monophasic defibrillation systems is stable over at least 2 years. ${ }^{49-11}$ However, the results with monophasic nonthoracotomy defibrillation systems are not as reassuring, ${ }^{1-4,6-8}$ and an increase in the defibrillation energy requirement may occur within 6 months of implantation. ${ }^{1-4,6}$ The defibrillation energy requirement in patients with nonthoracotomy biphasic defibrillation systems generally is noted to be stable for as long as 1 year., ${ }^{5,68}$ Among individual patients, however, the defibrillation energy requirement may increase by as much as $15 \mathrm{~J} .^{13-8}$

Heretofore, the stability of the defibrillation energy requirement beyond 1 year has not been reported with any type of implantable defibrillation system, including epicardial or nonthoracotomy systems. However, there are reports of elevated defibrillation energy requirements necessitating defibrillation system revision occurring more than 3 years after device implantation. ${ }^{12,13}$ The results presented herein suggest that the defibrillation energy requirement with biphasic nonthoracotomy systems is not always stable during the 2 years after implantation. Approximately $15 \%$ of patients may develop at least a 10-J increase in the defibrillation energy requirement between 1 and 2 years after device implantation.

\section{Defibrillation Energy Requirement Changes}

A variety of factors can affect defibrillation energy requirements. ${ }^{14-17}$ This study was not designed to identify the mechanism responsible for changes of the defibrillation energy requirement that occur over time. Although a change in the cardiac substrate or antiarrhythmic drug therapy could affect the defibrillation energy requirement, ${ }^{2-4,7,14,15,17-19}$ neither of these factors appeared to be responsible for the changes that occurred in the present study. Other possible explanations include changes at the

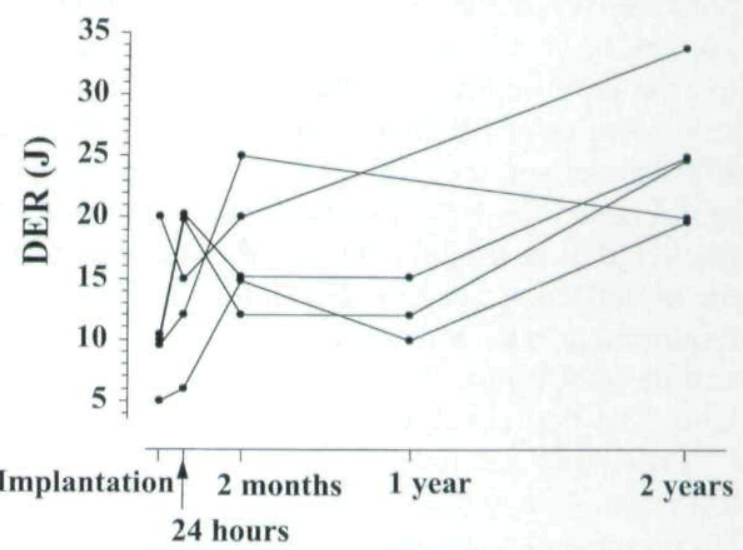

Figure 2. The individual defibrillation energy requirement (DER) data from the five patients in whom a 10-J or greater increase in the defibrillation energy requirement occurred. 
TABLE 1

Patient Characteristics

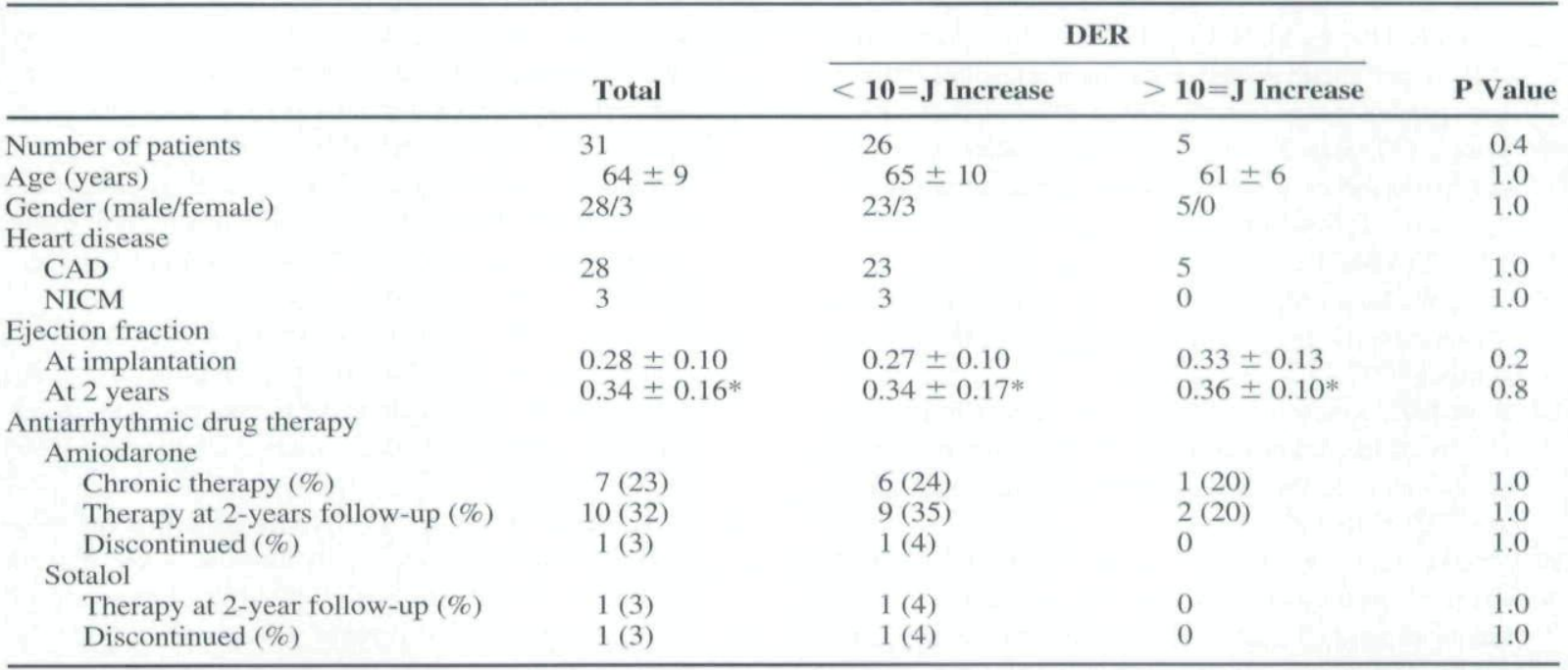

$\overline{\mathrm{CAD}}=$ coronary artery disease DER $<10=\mathrm{J}$ increase $=$ patients in whom DER did not increase at least $10 \mathrm{~J}$ during follow-up; DER $\geq 10=\mathrm{J}$ increase = patients in whom DER increased at least $10 \mathrm{~J}$ during follow-up; NICM = nonischemic cardiomyopathy.

$* \mathrm{P}=\mathrm{NS}$ versus ejection fraction at implantation.

electrode-myocardial interface, or changes in illdefined factors that could reduce the probability of successful defibrillation.

\section{Clinical Implications}

Given that an elevation of the defibrillation energy requirement of at least $10 \mathrm{~J}$ may develop in $15 \%$ of patients during the first 2 years after defibrillator implantation, periodic reevaluation of the defibrillation energy requirement may be appropriate. This is especially important for patients in whom the shock energy in the ventricular fibrillation zone is programmed to an energy associated with an adequate defibrillation safety margin, such as twice the defibrillation energy requirement, ${ }^{20,21}$ and not the maximum energy. In these patients, a $10-\mathrm{J}$ change in the defibrillation energy requirement may mandate a change in the programmed shock energy. ${ }^{20,21}$ However, these data are limited by the relatively small size. Therefore, additional studies with larger numbers of patients are required to assess stability of the defibrillation energy requirement beyond 2 years and to assess the longterm stability of the defibrillation energy requirement with other defibrillation.

\section{References}

1. Winter J, Vester EG, Kuhls S, et al: Defibrillation energy requirements with single endocardial (Endotak ${ }^{\mathrm{TM}}$ ) lead. PACE 1993;16:540-546.
2. Venditti FJ, Martin DT, Vassolas G, et al: Rise in chronic defibrillation thresholds in nonthoracotomy implantable defibrillator. Circulation 1994;89:216223.

3. Hsia HH, Mitra RL, Flores BT, et al: Early postoperative increase in defibrillation threshold with nonthoracotomy system in humans. PACE 1994;17:1166-1173.

4. Poole JE, Bardy GH, Dolack GL, et al: Serial defibrillation threshold measures in man: A prospective controlled study. J Cardiovasc Electrophysiol 1995; 6:19-25.

5. Martin DT, John R, Venditti FJ: Increase in defibrillation threshold in non-thoracotomy implantable defibrillators using a biphasic waveform. Am J Cardiol 1995; 76:263-266.

6. Schwartzman D, Callans DJ, Gottlieb CD, et al: Early postoperative rise in defibrillation threshold in patients with nonthoracotomy defibrillation lead systems. J Cardiovasc Electrophysiol 1996;7:483-493.

7. Kirk MM, Shorofsky SR, Khalighi K, et al: Chronic rise in monophasic defibrillation thresholds with a transvenous lead system. Am J Cardiol 1997;79:502504.

8. Gold MR, Kavesh NG, Peters RW, et al: Biphasic waveforms prevent the chronic rise of defibrillation thresholds with a transvenous lead system. J Am Coll Cardiol 1997;30:233-236.

9. Guarnieri T, Levine JH, Veltri EP, et al: Success of chronic defibrillation and the role of antiarrhythmic drugs with the automatic implantable cardioverter/defibrillator. Am J Cardiol 1987;60:1061-1064.

10. Wetherbee JN, Chapman PD, Troup PJ, et al: Longterm internal cardiac defibrillation threshold stability. PACE 1989;12:443-450. 
11. Frame R, Brodman R, Furman S, et al: Long-term stability of defibrillation thresholds with intrapericardial defibrillator patches. PACE 1993;16:208-212.

12. Goyal R, Harvey M, Horwood L, et al: Incidence of lead system malfunction detected during implantable defibrillator generator replacement. PACE 1996;19:1143-1146.

13. Daoud EG, Man KC, Morady F, et al: Rise in chronic defibrillation energy requirements necessitating implantable defibrillator lead system revision. PACE 1997;20:714-719.

14. Jung W, Manz M, Pizzulli L, et al: Effects of chronic amiodarone therapy on defibrillation threshold. Am J Cardiol 1992;70:1023-1027.

15. Raitt MH, Johnson G, Dolack GE, et al: Clinical predictors of the defibrillation threshold with the unipolar implantable defibrillation system. J Am Coll Cardiol 1995;25:1576-1583.

16. Strickberger SA, Brownstein SL, Wilkoff BL, et al: Clinical predictors of defibrillation energy requirements in patients treated with a nonthoracotomy defibrillator system. Am Heart J 1996;131:257-260.
17. Gold MR, Khalighi K, Kavesh NG, et al: Clinical predictors of transvenous biphasic defibrillation threshold. Am J Cardiol 1997;79:1623-1627.

18. Daoud EG, Man KC, Horwood L, et al: Relation between amiodarone and desethylamiodarone plasma concentrations and ventricular defibrillation energy requirements. Am J Cardiol 1997;79:97-100.

19. Dorian P, Newman D, Sheahan R, et al: d-Sotalol decreases defibrillation energy requirements in humans: A novel indication for drug therapy. J Cardiovasc Electrophysiol 1996;7:952-961.

20. Strickberger SA, Daoud EG, Davidson T, et al: Probability of successful defibrillation at multiples of the defibrillation energy requirement in patients with an implantable cardioverter defibrillator. Circulation 1997; 96:1217-1223.

21. Strickberger SA, Man KC, Souza J, et al: A prospective evaluation of two defibrillation safety margin techniques in patients with low defibrillation energy requirements. J Cardiovasc Electrophysiol 1998; 9:41-46. 
This document is a scanned copy of a printed document. No warranty is given about the accuracy of the copy. Users should refer to the original published version of the material. 